\title{
A Pragma-Dialectical Response to Objectivist Epistemic Challenges
}

\author{
BART GARSSEN
}

Department of Speech Communication, Argumentation Theory and Rhetoric

University of Amsterdam

Spuistraat 134

1012 VB Amsterdam

The Netherlands

Email: B.J.Garssen@uva.nl

\author{
Jan Albert Van LAAR \\ Department of Theoretical Philosophy \\ University of Groningen \\ Oude Boteringestraat 52 \\ 9712 GL Groningen \\ The Netherlands \\ Email: J.A.van.Laar@rug.nl
}

\begin{abstract}
Biro and Siegel have raised two objections against the pragmadialectical approach to argumentation. According to the first, the pragmadialectical theory is not genuinely normative. According to the second, the rejection of justificationism by pragma-dialecticians is unwarranted: they reject justificationism unjustly and they are not consistent in accepting some arguments ('justifications') as sound. The first objection is based on what we regard as the misconception that the goal of resolving differences of opinion cannot provide a normative perspective. In response to the second objection we argue that in pragma-dialectics, the notion of argument, and related notions, are defined in a non-justificatory manner.
\end{abstract}

Resumé: Biro et Siegel ont soulevé des objections contre l'approche pragma-dialectique de l'évaluation de l'argumentation. Selon la première objection, la théorie pragmadialectique n'est pas authentiquement normative. Selon la seconde, le rejet du justificationisme par les pragmadialecticiens est injustifié: ils rejettent à tort le justificationisme et ils sont incohérents lorsqu'ils acceptent certains arguments («justifications») comme étant probants. La première objection est fondée sur l'idée fausse que le but de résoudre des différences d'opinion ne peut pas fournir une perspective normative. En réponse à la seconde objection, nous avançons que dans la pragma-dialectique, la notion d'argument ainsi que d'autres notions reliées se définissent de façon nonjustificative.

(C) Bart Garssen and Jan Albert van Laar. Informal Logic, Vol. 30, No. 2 (2010), pp. 122-141. 
Keywords: Biro, critical rationalism, justificationism, Miller, Münchhausen trilemma, objective epistemic approach, pragma-dialectical approach, Siegel.

\section{Introduction: The epistemic challenge}

Since theories of argumentation deal with the question what counts as reasonable arguments, the choice of a specific philosophical reasonableness conception that underlies a theory of argumentation is of great importance and it can lead to intractable discussions among argumentation theorists. In the last two decades, epistemically oriented philosophers have voiced their criticisms of dialectically oriented argumentation theories at regular intervals. Among the most persistent are Biro and Siegel (Biro \& Siegel: 1992; 2006b; Siegel \& Biro: 2008). In this paper we shall give a reply from a pragma-dialectical perspective and show that the objections by Biro and Siegel against the dialectical project are based on incorrect assumptions.

Since we do not think that epistemology and dialectics are competing perspectives, it is surely not our intention to do away with epistemic approaches to argumentation. ${ }^{1}$ On the contrary, we take there to be many possibilities to integrate epistemological insights in dialectics and we believe that vice versa epistemology can profit from incorporating dialectical insights. ${ }^{2}$

Biro and Siegel's criticism of the pragma-dialectical approach to argumentation boils down to two objections. Although these are connected, we will discuss them separately. Firstly, they claim that the pragma-dialectical model is not genuinely normative for the reason that the norms that make up the model do not guarantee rational outcomes. Secondly, they claim that the pragma-dialectical approach does not and cannot live up to its aspirations derived from the critical rationalist philosophy.

\footnotetext{
${ }^{1}$ Neither do Biro and Siegel, who make it clear that they conceive of their epistemic approach and the pragma-dialectical approach as complementary, the former dealing with arguments as objects and the latter with the procedural requirements for arguing (2006b: p. 10).

${ }^{2}$ An example of a dialectical problem that could be solved by means of epistemological insights is the problem of specifying the dependency variants of circular reasoning, in which the acceptability of the premise 'depends on' the truth or acceptability of the standpoint. And, as Biro and Siegel point out (2006b: p. 9), the method of critical discussion might be of help to epistemology by providing a method for arriving at justified beliefs or knowledge. Freeman (2005) has shown how dialectical and epistemic insights can be integrated in order to evaluate the basic premises of argumentation.
} 


\section{The normativity claim in the pragma-dialectical argumenta- tion theory}

In the pragma-dialectical approach, argumentation is conceived of as a verbal contribution with which a speaker or writer, called the protagonist, makes an apparent attempt to convince an addressee, called the antagonist, of the acceptability of his standpoint, while pretending that this apparent attempt at convincing is part of a shared endeavor to resolve their difference of opinion on what they consider the merits of their respective positions. Central in this approach is the notion of a critical discussion, which explicates the normative idea of dispute resolution by specifying the various stages in the resolution process and the verbal moves that are instrumental in each of these stages. The philosophical background of this ideal model of critical discussion is critical rationalism, such as promoted by Popper. If one adopts the viewpoint of a critical rationalist "one pursues the development of a reasonableness model that takes the fallibility of human reason explicitly into account, and elevates the concept of systematic critical thinking in all areas of human thought and action the guiding principle of problem solving" (van Eemeren and Grootendorst 1988: p. 279).

In a critical discussion, a difference of opinion is "resolved" only if the parties have reached agreement on whether or not the protagonist's standpoint is acceptable vis-à-vis this particular antagonist, after having tested the standpoint's defensibility against the antagonist's doubts and criticisms. The rules for critical discussion are instrumental to this process of putting the standpoint and its defense to the test; discussion moves that obstruct this critical process are seen as unreasonable and called "fallacious".

One characteristic of the pragma-dialectical approach to argumentation is that arguments are not conceived of as mental processes, but as made up from statements that create public commitments. In this respect van Eemeren and Grootendorst follow Popper, who states that only publicly formulated theories are a suitable object of a critical discussion (van Eemeren \& Grootendorst 1982: p. 55; Popper 1979: p. 6, 31). As Popper states,

Subjective knowledge [consisting of dispositions and expectations] is not subject to criticism. Of course it can be changed - for example by the elimination (killing) of the carrier of the subjective knowledge or disposition. (...) As opposed to this, objective knowledge [consisting of linguistically formulated expectations] can change and grow by the elimination (killing) of the linguistically formulated conjecture: the 'carrier' of the knowledge can survive- he can, if he is a self-critical person, even eliminate his own 
conjecture. The difference is that linguistically formulated theories can be critically discussed. (1979: p. 66.)

In the pragma-dialectical approach to argumentation, terms such as 'justification', 'support' and 'argument' refer to inferences that have been made public in statements. When talking about 'dialectic', we refer to theories that purport to provide a normative model for such verbal, argumentative exchanges.

According to the picture sketched by Biro and Siegel, the pragma-dialectical argumentation theory is ambivalent between a reading that takes the normative dimension seriously, in which case the result is "in fact an epistemic [theory]" (2006b: p. 5), and a reading that takes the focus on agreement and resolution seriously, in which case the result is a theory that "collapses into a rhetorical one" (2006b: p. 4). According to Biro and Siegel, the pragmadialectical appeals to rationality, norms and reasonableness make it look like as if the theory offers a normative and even epistemic conception of argumentation, but its "pragmatic character runs counter to its apparent normativity" (1992: p. 90). The pragmadialectical theory is pictured as wavering between dialectical descriptivism and epistemic normativity, with an unhappy inclination to the first.

According to Biro and Siegel, "dissatisfaction with a formal conception of fallacy has led argumentation scholars, and pragmadialecticians among them, to look for pragmatic considerations of success or effectiveness, most often in terms of belief change on the part of the argument's audience" (Biro \& Siegel 1992: p. 87). They claim that it is tempting to see convincing one's audience as the goal that is essential to argument or argumentation (1992: p. 87). In such an approach the sole requirement, they claim, is causal efficacy, for example: is the argument efficacious in realizing a resolution in favor of either the antagonist or the protagonist, or is it not? But, so they contend, "There is no requirement that the change of belief be rational" (1992, p. 87). In Biro and Siegel's view, a rational change of belief, however, would require "a particular logical or epistemological relation between the argument and the change it causes" (1992, p. 87).

What is more, since the same argument can happen to succeed with one audience and fail with another, a "descriptive" approach such as the pragma-dialectical theory, leads to relativism. Fixing this problem by idealizing the theory will not work for persistent dialecticians. Either the norms or requirements that are added appeal, again, to the actual choices of the participants, and in that case the result remains descriptive and relativistic, or the added norms or requirements are independent of the contingent choices of the participants, and in that case the result is genuinely normative 
but, in fact, epistemic in nature and no longer dialectic, or so Biro and Siegel claim.

In Biro and Siegel's view, a crucial problem is that "the participants might abide by the code of conduct and resolve their dispute but in ways which render that resolution unjustified or irrational" (1992: p. 90). This can happen in two ways. First, where the disputants share and utilize false or unjustified beliefs, second where disputants accept to utilize problematic rules of reasoning or inference or other unacceptable arrangements (1992: p. 91). Biro and Siegel provide an example of the first type of problem:

Two disputants are arguing about the upcoming election. Both believe that the most handsome candidate (or the Black candidate, or the Jewish candidate, etc.) should be elected. They disagree, at the outset, about which candidate is most handsome and so most worthy of election; but after some discussion, during which the rules of the code of conduct are honored, the dispute is resolved and the participants agree that they should vote for candidate $\mathrm{C}$. (1992: p. 90.)

Biro and Siegel point out that the outcome of the discussion is patently irrational, since the participants' shared belief that handsomeness is an appropriate criterion is itself unjustified. In this case a resolution has been reached in accordance with the pragmadialectical code of conduct but this result of the discussion is "nevertheless unjustified or irrational" (1992: p. 90). This makes them conclude that pragma-dialectical rationality or reasonableness is not the kind of reasonableness we are after.

In the so-called opening stage of a critical discussion, the discussants are, indeed, free to draw up a list of propositions as being accepted by both parties. These 'material starting points' may not be called into question during the discussion and only the propositions that are on this list may be used in the argumentation without further justification. This means that when there is an intersubjective agreement on the acceptability of a premise (starting point), discussants can use this starting point as a premise in the argumentation without further justification. ${ }^{3}$ In the election example, the discussants agreed on the acceptability of the premise "the most handsome candidate is the best candidate" and therefore the use of this starting point does not go against the pragma-dialectical norms. Biro and Siegel's argument is that argumentation theories

\footnotetext{
${ }^{3}$ In specific contexts there may be special constraints that limit the choice of starting points. For example, we can choose to resolve an issue merely by resource to observational accounts, or to a priori considerations, or to legally obtained evidence, etcetera.
} 
that allow absurd assumptions cannot be normative or at least not fully normative, and are at least partly descriptive and relativistic. Apparently, a really "normative" argumentation theory should provide provisions that stop discussants from agreeing on principles that can be called absurd.

The conclusion that the pragma-dialectical approach is, in the end, descriptive and relativistic is not justified. The outcome of a critical discussion is not an absolute result, but it is partly dependent on the chosen material starting points accepted as not being in need of support or criticism. There is a good reason for choosing to conceive of argumentation as being potentially non-fallacious even in case the argumentation is based upon starting points that we, as onlookers or analysts, consider unacceptable. It is in situations where we lack generally agreed upon criteria with which to decide upon the truth or falsity of propositions, that argumentation is pertinent. We want to be able to evaluate arguments in situations where matters are contentious or uncertain and where we cannot be sure that our preferred criteria for what is true or otherwise worthy of our commitment are correct.

We leave it up to the various disciplines to provide methods and criteria that help scholars to assess the acceptability of premises, and we leave it up to individual disputants to create what they conceive of as an appropriate common ground. But we assign argumentation theory the task of examining how to converse reasonably on the basis of whatever is deemed acceptable by parties. At any rate, this does not make the pragma-dialectical theory of argumentation descriptive or relativistic. The freedom to adopt material starting points is regulated by the general norms for critical discussion, and only making these general norms dependent upon audiences, rather than making the material starting points dependent upon audiences, would make a theory genuinely relativistic and that is clearly not what happens in the pragma-dialectical approach. So, we consider it argumentatively acceptable for two voters to commence from the idea that their dispute is to be resolved by deciding on which candidate is most handsome. Absurd as the case may be, argumentation theorists should not, a priori, rule out the possibility that this point of departure is correct. (Possibly, handsomeness turns out to be indicative of political strength.) The norms for critical discussion are universal in the sense that they constitute the ideal of critical discussion that is applicable to argumentation in all settings.

The second type of problem Biro and Siegel mention arises where the arguers reach an unjustified outcome because they use incorrect reasoning schemes or inference rules, such as schemes enabling the discussants to agree on outcomes that, as a matter of fact, are the result of the gambler's fallacy (1992: p. 91). Even though the model for critical discussion allows the parties some 
latitude when deciding upon logical issues in the opening stage, there is a general requirement according to which the adopted logical schemes or argument schemes possess so-called 'problem validity.' The notion of problem validity (Barth \& Krabbe 1982) is used by van Eemeren and Grootendorst $(2004$ : pp. 22, 134) to refer to discussion rules that are instrumental for resolving differences of opinion, including rules that concern the logical or argumentative relations between propositions. If arguers start from logical schemes or argument schemes that lack problem validity, the result of the discussion is at most a pseudo-resolution.

That a (logical or argumentation) scheme is problem valid we take to mean that the adoption of the scheme ${ }^{4}$ is instrumental for the resolution of the dispute. We restrict attention to argumentation schemes although something similar can be said for logical schemes (see Barth \& Krabbe 1982). For example, the pragmatic argumentation scheme provides the protagonist of a standpoint to the effect that a certain action ought to be carried out, with a premise that points out that carrying out the action has particular consequences and a premise that points out that these consequences are preferable to the consequences of refraining from that action. An argumentation scheme is associated with a set of critical question with which these reasons, and their justificatory force for the standpoint at hand, can be tested by the antagonist. One type of critical question connected with the pragmatic scheme concerns whether the consequences of the proposed action are preferable, as alleged by the protagonist.

Adopting the scheme is problem valid insofar as the scheme enables the parties to offer arguments that promote criticisms in line with points of departure adopted by the parties. The pragmatic scheme has a clear structure, and a clear set of critical question with which to test it, thereby satisfying a general requirement for argument schemes. Moreover, if the protagonist and the antagonist share the point of departure that practical issues are to be decided by weighing the actions' consequences, the scheme leads the participants to take the pertinent considerations into account. (For parties who choose to resolve practical issues only by deontic measures, the pragmatic scheme could possibly lack problem validity.) So, the scheme is problem valid, not because it is an objective fact that practical issues can be decided by weighing the utilities of the options for action and because applying the scheme leads the parties to the best possible outcome, but because the scheme helps the participants to critically assess proposals for action from their consequentialist stance. It helps them to weed out errors regarding the assignment of consequences to actions and of values to conse-

\footnotetext{
${ }^{4}$ More precisely: the adoption of the rule according to which employing that scheme is admissible.
} 
quences. Note that this explication of problem validity does not employ the terminology of seeking for justifying reasons, but is formulated entirely in terms of critical testing, a characteristic of the pragma-dialectical approach that will be dealt with further in Section 3.

Therefore, the use of argumentation or logical schemes is, unlike the choice for material starting points, not a matter of mere agreement between participants, although for a resolution this agreement is a necessary condition, but a scheme has as an additional requirement that it furthers critical testing. The problem validity of the discussion rules in general, and of the appropriateness of the argumentation and reasoning schemes in particular, is the result of assessing them, not in view of their epistemic worth, but rather in view of the degree to which they promote criticism, something insufficiently appreciated by Biro and Siegel, in our opinion.

By the way, from the (in our eyes unjustified) conclusion that, in pragma-dialectics, what counts as reasonable depends on the accidental participants in the discussion, Biro and Siegel conclude that we need an epistemic approach to argumentation if we want a normative account of argumentation. The epistemic alternative is based "on the claim that is a conceptual truth about arguments that their central (not, of course, only) purpose is to provide a bridge from known truths or justified beliefs to as yet unknown (or at least unrecognized) truths or as yet unjustified beliefs" (1992: p. 92). What is striking about this view is that it seems to imply an unacceptable restriction of the type of issues that can be raised in discussion. Political or legal argumentation that is put forward in defense of practical standpoints seems to be disregarded. For it is only in a stretched use of the term that we can say that it is true that something ought to be done or that the prudence of an action is the object of a belief. ${ }^{5}$ What is more, from a dialectical stance, the notions "known truth" and "justified belief" need further clarification. Who is to decide that a certain statement is a "known truth" or a "justified belief," in case the matter is contentious? We will come back to this issue when dealing, in the next section, with Biro and Siegel's critique of the philosophical underpinnings of the pragmadialectical theory.

\footnotetext{
${ }^{5}$ Freeman's epistemological argumentation theory (2005) fares better in this respect, because he considers 'acceptability' as the central notion when evaluating premises.
} 


\section{The rejection of justificationism in the pragma-dialectical approach}

Biro and Siegel's second objection to the pragma-dialectical approach concerns van Eemeren and Grootendorst's rejection of justificationism as a philosophical point of departure of argumentation theory, as this can be found for example in A Systematic Theory of Argumentation (van Eemeren \& Grootendorst 2004: p. 131). Justificationism, according to Albert, amounts to the adoption of the following principle: "always seek an adequate foundation-a sufficient justification-for all your convictions" (1985: p. 14). In the view of justificationists, arguments are vital as the means for generating the justifications that are needed to conform to this principle. A good argument can, in this light, be seen as an argument that provides a sufficient justification for some conviction. In Bartley's words, justificationism can be characterized as the kind of philosophy that is concerned with providing the criteria for answering questions of the kind "How do you know?" (Bartley: 1984, p. 113)

Instead of justificationism, van Eemeren and Grootendorst opt for critical rationalism as the appropriate, non-justificatory philosophical point of departure for studying argumentation. Bartley called his alternative to justificationism 'pancritical rationalism' and he presented it as an enhanced version of Popper's critical rationalism. Pancritical rationalism is the kind of philosophy that has as its central question:

How can our intellectual life and institutions be arranged so as to expose our beliefs, conjectures, policies, positions, sources of ideas, traditions, and the like-whether or not they are justifiable - to maximum criticism, in order to counteract and eliminate as much intellectual error as possible? (Bartley: 1984, p. 113.)

The model for critical discussion that van Eemeren and Grootendorst developed can be understood as their proposal for an arrangement that promotes criticism, in a way indicated by Bartley. Dialectic, as we conceive of it, is the study of conversational norms that promote criticism.

Biro and Siegel's objection against the rejection of justificationism is twofold, and we will deal with these objections in more detail in the sections below. First, they hold that it is not possible to reject justificationism and, at the same time, to accept arguments as potentially sound. By rejecting justificationism, the pragmadialectical theory undermines its own position.

To reject 'justificationism' in the sense of positive justification would be devastating to their [van Eemeren and 
Grootendorst's] project in at least two ways: it would undercut the possibility of any argument(ation) succeeding in the sense of providing interlocutors with good reasons to accept or reject any given standpoint at issue; and it would undercut their own many impressive efforts to defend the pragma-dialectical view they champion. (Siegel \& Biro: 2008, p. 199.)

Moreover, Biro and Siegel suggest that there is a 'whiff' of justificationism in the pragma-dialectical theory by pointing out that Popper himself had to concede there to be a 'whiff of inductivism' in his critical rationalist philosophy of science.

Second, Biro and Siegel believe that the rejection of justificationism rests on a mistake. According to pragma-dialectics, a justificationist is forced to choose from three evils, represented in the so-called 'Münchhausen trilemma'. We will elaborate on this in the next section. However, Biro and Siegel take it that the pragmadialectical theory overlooks a fourth option: "we think $M T$ [the Münchhausen trilemma] can be readily overcome" (2008: p. 199). Put differently, there is a way out of the trilemma.

In Section 3.1, we discuss the Münchhausen trilemma in order to determine what the rejection of justificationism amounts to. We show in Section 3.2 how in the pragma-dialectical theory on the one side justificationism is being rejected and on the other there is talk of 'pro-argumentation' and 'justificatory force', in what we consider a consistent manner. Here we shall also try to show that there is not even a whiff of justificationism in pragma-dialectics. This provides us with our answer to the challenges concerning the consistency of the pragma-dialectical program. Finally, we will show in Section 3.3 how the supposed fourth escape route is not really a way out but in fact a turn to a dialectical starting point.

\subsection{The Münchhausen trilemma}

The pragma-dialecticians have rejected justificationism by reference to the Münchhausen trilemma. We will explain what this trilemma amounts to and point at two shortcomings that, in our view, lie at the bottom of the failure of justificationism.

Following Albert, van Eemeren and Grootendorst explain that each version of justificationism falls victim to one of the three horns of the Münchhausen trilemma (1988: p. 279). Baron Münchhausen boasted that he had pulled himself up from a swamp by his own hair, and his horse with him. The justificationist principle is considered as impossible to follow as the imaginary accomplishment of the baron. This forms a reason to choose for an alternative philosophical point of departure. 
According to the trilemma, a justificationist is forced to choose from three evils. The first option is to accept that each justifying reason must be supported itself with further reasons. The ultimate consequence of this choice would be an infinite regress of supporting reasons being supported by reasons, for how could a justificationist turn down his own requests for further support? The second option is to state, at some point or other, that a supporting argumentation is plausible to such a level that it carries its own support. One might suppose that some assertions are incorrigible, for example because they express fully accurately what one has perceived, or because they cannot be denied, or even challenged, in a consistent way. In such cases, one, in effect, abandons the justificationist's principle and succumbs to what Albert refers to as a dogma. The third option is to support a supporting reason by the proposition that this reason is supposed to support. Such circular reasoning enables one to create a situation where all propositions get some support, but the result does not contain a genuinely justified conclusion. The upshot of the Münchhausen critique is that the adoption of justificationism leads one into insurmountable problems.

In our view, the trilemma provides a sketch of the types of problems that must be dealt with when adopting the justificationist principle. The dismissal of justificationism can further be argued for by pointing at the fallibility of our convictions and theories. (Below it will become clear in what non-justificationist sense we understand our own arguing). We could be wrong, also with our most cherished opinions and most obvious assumptions. It is especially useful to take fallibilism as seriously as possible when it comes to controversial topics. Even if the quest for justification can be reconciled with the acknowledgement that humans are fallible, critical rationalism constitutes an approach that takes the fallibility of our cognitive capacities more seriously than justificationism. For the central idea in the critical approach is that opinions and theories must be tested systematically and critically, and that sound arguments should be understood as contributions to such a critical examination. Merely acknowledging the possibility of shortcomings in a justification does not suffice. That is why argumentation should be situated in the kind of discussion where an antagonist has adopted the task of finding out whether the protagonist's standpoint is acceptable, and whether the argumentation offered in support of the standpoint is sound. A weakness of justificationism is therefore that the attention is fixed on justification rather than on criticism. ${ }^{6}$

\footnotetext{
${ }^{6}$ We appreciate Freeman's detailed epistemological account of premise acceptability for incorporating defeaters, which makes his theory explicitly fallibilist. In his view, a premise is 'acceptable just when there is a presumption in its favor' (2005: p. 21). The notion of presumption of a statement is, following Plantinga, in part explicated in terms of the presumptions pertaining to the mechanisms which have generated the belief at hand (and in part by a pragmatic crite-
} 
A second, though related, weakness is that justificationists do not pay sufficient attention to the addressee, and his points of departure. According to the pragma-dialectical approach, an attempt at justification can only be said to be successful, given a collection of propositions that function as the material starting points and a set of norms, in addition to the norms for critical discussion, that function as the procedural starting points (van Eemeren \& Grootendorst 2004: p. 143). The material and procedural commitments that the participants in a critical discussion adopt can be seen as the frame in which they are examining the acceptability of the standpoint. Both types of starting points can themselves be chosen as a topic for discussion (either in a subdiscussion or in a separate discussion) and are, consequently, not immune to criticism. Instead, in justificationism, as Biro and Siegel seem to conceive it, it is assumed that the quality of argumentation is not to be judged by determining whether it is based on what an antagonist happens to be willing to commit himself to, but, at least in the ideal case, by determining whether the argumentation satisfies the objective criteria (true starting points and the truly reliable argument and reasoning schemes). The choice for taking fallibility as seriously as possible incites us to adopt the first stance. Each proposal for accepting would-be objective argumentative criteria must be considered as disputable, if not here and now then on different occasions, and consequently as a position within a discussion. (The pragmadialectical proposal for a collection of rules for critical discussion itself is a position in discussions about argumentative reasonableness.)

The pragma-dialectical criticism against justificationism is not that it would be impossible to bring forward good reasons in support of a standpoint. The criticism is that the focus is on good reasons, conceived of as in a socially void space, instead of argumentation as a response to criticisms by a particular antagonist. We will elaborate on this in the next section.

\subsection{Is the pragma-dialectical theory a disguised form of justifica- tionism?}

rion). Absent defeaters, beliefs that are generated by reliable mechanisms that are designed for generating truths and that function properly within suitable circumstances, are considered acceptable. However, what makes a critical rationalist perspective more fallibilist is that it focuses on publicly testable statements and that it leaves it open for a party to even challenge statements that correctly express beliefs generated by the mechanisms just sketched. An antagonist might do so for skeptical reasons, or when he is motivated by judicial considerations, for example. 
Biro and Siegel's opinion is that there is no room for a notion of positive argumentation or justification in the pragma-dialectical approach, if it is to be genuinely critical rationalist. They support this view by referring to remarks about arguments by the critical rationalist philosophers Popper and Miller. First, we will make it clear that Biro and Siegel are correct in interpreting pragmadialectics as rejecting justification as the proper aim of arguments, rather than merely rejecting justification with certainty. ${ }^{7}$ Still, 'argument', 'pro-argumentation', 'justificatory force,' and related expressions, have in pragma-dialectics been provided with a nonjustificationist meaning, as we will show. Finally, we will invalidate the suggestion that there is a whiff of justificationism in the pragma-dialectical approach.

Biro and Siegel distinguish between a weak and a strong form of justificationism (2008, p. 197). According to the strong version, we ought to strive for theories or standpoints that are certainly true; according to weak justificationism, which they themselves defend, we ought to strive for justification, whether this pursuit is accompanied by a quest for certainty or whether one is satisfied with justifications that are inductively strong or considered adequate in different ways. Does the pragma-dialectical theory only reject the strong version, or also the weak one?

Biro and Siegel correctly point out that critical rationalism extends beyond the mere rejection of the quest for certainty. Popper and Miller explicitly opposed an inductivist or probabilistic elaboration of justificationism. Also in Albert's reading, justificationism includes non-deductivist variants. Biro and Siegel are therefore correct in characterizing critical rationalism as the rejection of even the weaker form of justificationism (Biro \& Siegel 2008: pp. 195-197; 201-202) and in interpreting the Münchhausen argumentation as targeting each form of justificationism. Also pragma-dialectics can be seen as starting from a rejection of weak justificationism.

However, different from what Biro and Siegel hold (and, apparently, Lumer with them, 2009, n. 10), there is room for a notion of positive argumentation within the pragma-dialectical development of critical rationalism. The use of expressions such as 'argument', 'pro-argumentation', and 'justificatory force', does not show a hidden commitment to (the weak form of) justificationism. First, we will show that even the critical rationalist Miller, referred

\footnotetext{
${ }^{7}$ Their arguments for this interpretation are that only this interpretation makes it possible to explain why van Eemeren and Grootendorst invoke the Münchhausen trilemma and why they call themselves 'critical rationalists'. Moreover, if van Eemeren and Grootendorst would merely reject strong justifications, their philosophy would have been epistemic in nature, which runs counter to the dialectical criteria of reasonableness defended by van Eemeren and Grootendorst (2008: p. 202).
} 
to by Biro and Siegel when arguing that critical rationalists do and should reject all arguments, allows room for a particular notion of argument. Second, we will deal with the pragma-dialectical perspective itself and show that these terms have been provided with meanings that cohere with the critical rationalist outlook of the theory.

Miller defends the thesis that argumentation should only fulfill a critical function. He has a narrow view ${ }^{8}$ on what counts as critical: with a "critical argument" one tries to deduce a false consequence from an hypothesis $(\varphi \rightarrow \psi$ and $\neg \psi)$, thereby proving the falsity of hypothesis $(\neg \varphi)$. In addition, Miller allows for a special type of critical argumentation he characterizes as "defensive argument," which is a critical argument aimed at refuting another critical argument. A defensive argument reasons towards either the denial of the statement that expresses that the hypothesis' consequence is false (so an argument with $\neg \neg \psi$ as its conclusion) or to the denial of the statement that expresses that the hypothesis leads to the consequence (so an argument with $\neg(\varphi \rightarrow \psi)$ as its conclusion). An exchange of such "critical" and "defensive" arguments does not suffer from the defects of justificationism, according to Miller. The main defect of justificationist thinking is that, in so far as a justification is logically valid (and Miller takes validity to be a necessary condition for reasoning), the supporting argumentation must contain all information that is expressed in the conclusion. Due to this inevitable "circularity," a chain of justifications keeps revolving around the same bits of information. Instead of stimulating an exploring attitude in order to find errors and mistakes, justificatory thinking entrenches oneself deeper and deeper. The dialectic of "critical argument" and "defensive argument," however, incites the participants to search for new information with which to refute the other side and decide the dispute. The examination is critical and directed towards fresh data (Miller 1994: pp. 66-69; Miller 2006: p. 76-79). So, even on Miller's account, there is room for argumentation. In the pragma-dialectical theory, arguments are assessed from a perspective that resembles the critical spirit of Miller but that starts from a more inclusive notion of criticism.

According to the pragma-dialectical theory, argumentation must be examined from the perspective of a critical discussion. Within a critical discussion, the range of critical devices at the disposal of the participants extends beyond deducing the denial of a

\footnotetext{
${ }^{8}$ In our view Miller expresses an overly negative stance towards positive argumentation, suggesting that each form of support or attempt at persuasion is suspicious and never functional to critical examination (Miller 2006, Chapter 3). This negative view stems from an all too narrow view of criticism. As will become clear, we take it that positive arguments are sometimes functional from a critical perspective.
} 
standpoint, deducing the denial of the denial of a logical consequence of the standpoint or deducing the denial of the connection between standpoint and the would-be consequence. In a critical discussion, the position of the protagonist is to be tested: (1) by posing a critical question, either directed at the standpoint or at a supporting reason or at the chosen argumentation or logical scheme; (2) by requesting linguistic clarification from the protagonist; (3) by offering argumentation for either the denial of the standpoint or the denial of a supporting reason; and (4) by challenging the legitimacy of the argumentation, for example by way of a fallacy charge. Consequently, there is a larger inventory of moves that can have a useful role in a critical examination of the acceptability of a standpoint. The similarity with Miller's view is that argumentation is situated in a critical, dialectical kind of encounter.

Due to this dialectical setting, the argumentative terminology has been provided with content that is not justificationist in character. First, the protagonist puts forward argumentation in response to challenges by the antagonist. It is the antagonist who, by posing critical questions, objections and requests for clarification, points at the components of the protagonist's position that are considered in need of further support or clarification. In short, argumentation, in the dialectical sense of the term, is not an attempt to find a more or less firm foundation, but nothing more nor less than coping with criticism.

Second, argumentation is part of a cooperative examination into the issue of whether the standpoint of the protagonist is to be accepted by the antagonist, given the starting points that the parties have agreed upon in the opening stage. Even though there is nothing to defend for the antagonist in a non-mixed discussion and there is not a kind of burden of proof for his critical stance, the antagonist does have an argumentative position. In the argumentation stage, it is up to the antagonist to maintain and elaborate his critical position in a consistent manner in spite of the argumentation put forward by the protagonist. Consequently, the argumentation of the protagonist contains a critical aspect, in so far as it forms a test of the feasibility of this aspiration of the antagonist in the argumentation stage. Like Miller, we say that all good arguments are "critical" and aimed at testing the critical position of the antagonist. In short, argumentation forms a part of a mutual investigation into the acceptability of a standpoint, and therefore into the tenability of both the position of the protagonist and of the antagonist. Different from what Biro and Siegel seem to suppose (2008), critical rationalistic argumentation theorists do not need to avoid all uses of terms such as 'argument', 'pro-argumentation' and 'justificatory force'.

Of course, justificationists also assign a role to criticism by stressing the importance of the question "how do you know that 
P?" when P has been offered as a thesis or as part of a justification. Bartley distinguishes between "justificational philosophies of criticism" (1984, p. 116), where criticism is considered the same as a demand for justification, and nonjustificational philosophy of criticism (p. 117), where criticism is aimed at eliminating errors and not at positive justification. It is clear that in our understanding, "criticism" aimed at weeding out errors is primary and that argument is better seen as a by-product of the critical process than as the device with which to guarantee a position in a secure enough foundation.

This dialectical explication of 'argumentation' also provides the main ingredient of our response to Biro and Siegel's criticism according to which critical rationalism is in need of a notion of justification (2008: pp. 197-8). Biro and Siegel remind us of Popper's acknowledgement that his critical rationalism does not remain fully free from inductivism (and thereby from justificationism), namely in so far as Popper had to concede that a scientific theory or hypothesis that has withstood serious attempts at refutation, and has thus been "corroborated," can be seen as having more "truthlikeness" as compared to less successful theories (NewtonSmith 1981, p. 67-8). There is thus a "whiff of inductivism" in Popper's position. Biro and Siegel seem to suggest that a similar concession to justificationism should be appropriate for pragmadialectics. Even though the authors do not spell out the (parallel) argument that should force pragma-dialecticians to make this (parallel) concession, in our interpretation it must be something along the following lines. Presumably, the pragma-dialectical problem would be that it must accept a special kind of justification as acceptable, contrary to its critical aspirations. For, suppose that a critical discussion results in a resolution in favor of a protagonist who has defended a standpoint $\mathrm{S}$ (the analogue of a corroborated hypothesis). Then pragma-dialecticians would have to accept that this outcome of the discussion constitutes a justification of standpoint S's acceptability (the analogue of an hypothesis that can be considered as having an increased "truthlikeness"). What is more, given that it is our interest in acceptable standpoints that motivates us to resolve differences of opinion, pragma-dialectics generates such special kinds of justifications in its quest for acceptable standpoints. However, we do not think this problem arises.

First, in a dialectical sense of 'justify', the outcome of a discussion can, indeed, (but need not) be used to justify a proposition. This is not indicative of a whiff of justificationism. Suppose, two discussions, D and D', have been conducted, such that the protagonist in $\mathrm{D}$ defends that $\mathrm{S}$ while the protagonist in $\mathrm{D}$ ' defends that not-S. Suppose further that both discussions proceed from starting points that some person $\mathrm{P}$ underwrites, that all propositions that $\mathrm{P}$ considers relevant for this issue are in fact starting points of $\mathrm{D}$ and 
D', that the parties in $\mathrm{D}$ and $\mathrm{D}$ ' have performed the moves that $\mathrm{P}$ would consider the pertinent moves, and that $\mathrm{D}$ and $\mathrm{D}$ ' do not contain any violation of a rule for critical discussion. Finally suppose that $\mathrm{S}$ has been defended successfully in $\mathrm{D}$ but that not-S has not been defended successfully in $\mathrm{D}^{\prime}$ (or that $\mathrm{S}$ has been defended more successfully in D as compared to how not-S has fared in D'). Then, other things being equal, it can be expected that this person $\mathrm{P}$ will prefer $\mathrm{S}$ as his personal conviction over not-S. A person, $\mathrm{Q}$, could even try to convince $\mathrm{P}$ of $\mathrm{S}$ by referring to these discussions $\mathrm{D}$ and $\mathrm{D}$ ' and their outcomes. That way of arguing could be a success for Q.

The fact that this kind of argumentation can be in line with the norms for critical discussion, however, does not mean that the pragma-dialectical approach allows for a "whiff of justificationism". Every argument can be understood as part of a mutual, critical examination, and this special argument (that takes the outcome of $\mathrm{D}$ and D' as its starting points), too, should be seen as a response to an antagonist $(\mathrm{P})$ who is testing the standpoint critically. So, the special argument does not constitute justification, unless we understand this term in a dialectical fashion.

Second, the parties' interest in resolving differences of opinion is not necessarily motivated by the aim of arriving at true or acceptable standpoints. We readily agree that critical discussions can be instrumental for dialogue participants who are primarily interested in finding out whether the standpoint at issue is acceptable "as such" (i.e., expressing a true proposition, or an action that is really recommendable, or an evaluation that is genuinely appropriate), rather than merely defensible against a particular antagonist with particular starting points. But this aim for a standpoint that is "as such" acceptable is not the goal of critical discussion as defined in pragma-dialectics. The desired result of any critical discussion is either that the standpoint has been successfully defended against an antagonist who has been committed himself to a particular set of starting points, or that the standpoint has been successfully criticized from that particular stance. So, different from Popper's philosophy of science, which is motivated by the quest for true theories, the pragma-dialectical theory of argumentation remains restricted to the investigation of standpoints in the light of particular sets of starting points. Given that the pragma-dialectical theory is about defending standpoints against an addressee with a particular set of commitments, rather than about trying to approach true theories or standpoints that are acceptable as such, there is not even a whiff of justificationism in pragma-dialectics. In short, argumentation must be understood from the intended, critical perspective and the argumentative expressions used do not imply any concession to justificationism, other than that expressions such as 'justificatory force' are useful ones. 


\subsection{The way out of the dilemma}

According to Biro and Siegel, the justificationist has a fourth option when facing the Münchhausen problem, and one that does not have the drawbacks of the other three. So, it is not really a trilem$\mathrm{ma}$, and there is no need to give up justificationism. We will make it plausible that the escape route that Biro and Siegel construct is only enabled by introducing a dialectical, non-justificationist consideration. Put differently, we do not think this escape route is available to justificationists.

The authors illustrate their fourth way with an example. A proposition $q$, "Cheney lobbied Senators to defeat the McCain amendment prohibiting torture," is supported with a proposition $r$, "Cheney admitted his lobbying efforts and resigned". Of course, so they say, this reason itself can also be criticized, and in such a case a link is to be added to the chain of justifications. But, "absent some such further challenge [...] $r$ is justified" $(2008$, p. 200). Absent such a challenge, proposition $r$ forms a non-arbitrary and noncircular endpoint.

We agree that the situation could be such that $r$ is not in need of argumentation, namely, to be specific, if the antagonist has committed himself to $r$ as a starting point, or if the antagonist, as a matter of fact, does not challenge $r$. But to our mind, a motivation of this kind only succeeds when having adopted a dialectical background. From a dialectical stance it is clear where the protagonist can stop putting forward further arguments: when having arrived at the mutually agreed upon starting points of the discussion. From a justificationist stance, where no clear role is assigned to a critical antagonist, it cannot be made clear that $r$ does not stand in need of support. Because, a justificationist response to Biro and Siegel's proposed solution could go: "What does it matter whether or not $r$ happens to be addressed to an audience that, as a matter of fact, does not challenge $r$ ? The real issue is the objective truth and since $r$ 's truth has not yet been guaranteed, we ought to justify $r$ ". So, we fail to see a fourth way that is genuinely justificationist. ${ }^{9}$

\section{Conclusion}

Biro and Siegel have raised two objections against the pragmadialectical theory of argumentation. According to the first, the the-

\footnotetext{
${ }^{9}$ Biro and Siegel point out the similarity between the resolution of the trilemma they propose and Popper's emphasis on basic statements (2008, p. 200). Given the structural similarity between Popper's basic statements in his philosophy of science and the accepted starting points in the model of a critical discussion, we regard this as being in line with our contention that a dialectical element lies at the basis of the alleged fourth way out of the dilemma.
} 
ory is not genuinely normative. According to the second, the pragma-dialectical rejection of justificationism is unwarranted. The first objection is based on what we regard as the misconception that resolution is not a normative notion. As far as the second kind of objection is concerned, the authors do not seem to acknowledge that the notion of argument, and related notions, have been defined in a non-justificatory manner and that the alleged escape route from the Münchhausen trilemma is only possible after having introduced a dialectical consideration.

\section{Acknowledgements}

We want to thank the two anonymous referees for their useful suggestions and comments.

\section{References}

Albert, H. (1985). Treatise on critical reason. Princeton, N.J: Princeton University Press

Barth, E.M. \& E.C.W. Krabbe (1982). From axiom to dialogue: A philosophical study of logics and argumentation. Berlin: De Gruyter.

Bartley, W.B., III (1984). The retreat of commitment. La Salle and London: Open Court. (Second, revised edition. First published in 1962.)

Biro, J. \& H. Siegel (1992). Normativity, argumentation and an epistemic theory of fallacies. In: F.H. van Eemeren, R. Grootendorst, J.A. Blair \& C.A. Willard (Eds.), Argumentation illuminated (pp. 85-103), Amsterdam: Sic Sat.

Biro, J. \& H. Siegel (2006a). In defense of the objective epistemic approach to argumentation. Informal Logic 26, 91-101.

Biro, J. \& H. Siegel (2006b). Pragma-dialectic versus epistemic theories of arguing and arguments: Rivals or partners? In: P. Houtlosser \& A. van Rees (eds.), Considering pragmadialectics (pp. 1-10), Mahwah: Lawrence Erlbaum.

Eemeren, F.H., van \& R. Grootendorst (2004). A systematic theory of argumentation. The pragma-dialectical approach. Cambridge: Cambridge University Press.

Eemeren, F.H., van \& R. Grootendorst (1988). Rationale for a Pragma-Dialectical Perspective. Argumentation 2, 271-191.

Eemeren, F.H., van \& R. Grootendorst (1982). Regels voor kritische discussie. Dordrecht: Foris.

Freeman, J.B. (2005). Acceptable premises: An epistemic approach to an informal logic problem. Cambridge: Cambridge University Press. 
Pragma-Dialectical Response to Objectivist Challenges 141

Lumer, C. (2009). Pragma-dialectics and the function of argumentation. In: Argumentation 24, 41-69.

Miller, D. (1994). Critical rationalism: A restatement and defence. Chicago: Open Court.

Miller, D. (2006). Out of error: Further essays on critical rationalism. Aldershot: Ashgate.

Newton-Smith, W.H. (1981). The rationality of science. Boston: Routledge; Kegan Paul.

Popper, K.R. (1972). The logic of scientific discovery. London: Hutchinson. (First published in 1959)

Popper, K.R. (1979). Objective knowledge: An evolutionary approach (Revised edition; First published in 1972)

Siegel, H. \& J. Biro (2008). Rationality, reasonableness, and critical rationalism: Problems with the pragma-dialectical view. Argumentation 22 (2), 191-202. 